\title{
CANS:
}

The linings of most of these still contain the controversial chemical BPA.

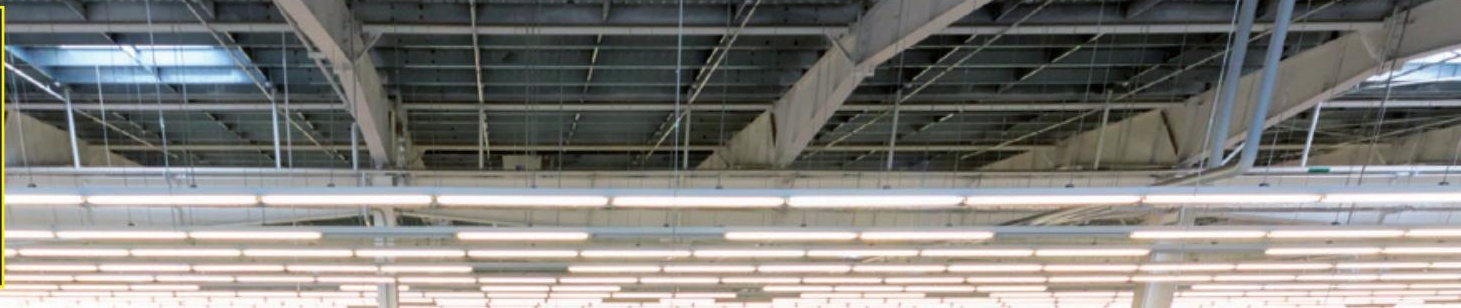

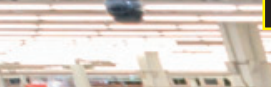

-

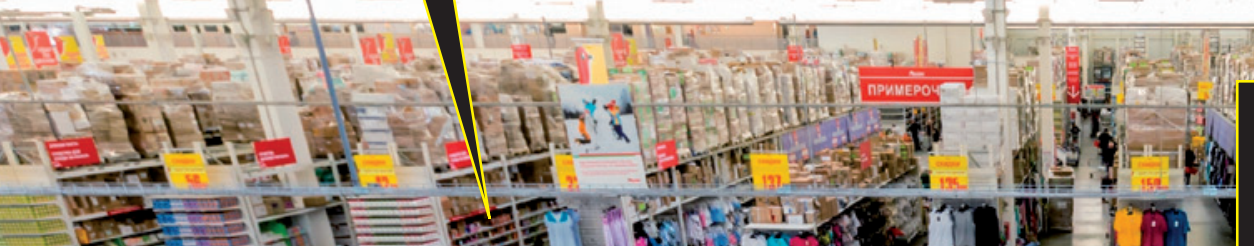
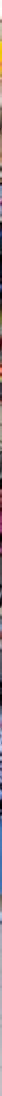

RECEIPTS:

Many contain

BPS, a compound

that is structurally

similar to BPA.

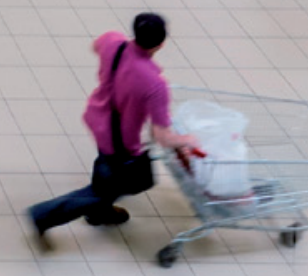

When toxicologists warned that the plastics ingredient BPA might be harmful, consumers clamoured for something new. But problems persist. 
A stroll down the aisles of a US supermarket reveals a modest victory for consumer activism. In the baby-products section, plastic baby bottles, spill-proof cups and miniature cutlery are proudly marked 'BPA-free' - a sign that they no longer contain the compound bisphenol A, found in many plastics. A range of blenders and water bottles in the kitchenware aisle are also untainted by the chemical, as are a few cans of beans tucked away in the organic foods section. And customers filling their baskets with these BPA-free treasures may even receive a BPA-free receipt at the cash register.

The partial withdrawal of BPA is the culmination of two decades of research and hundreds of studies linking the compound - which mimics sex hormones called oestrogens - to adverse health effects in rodents and humans. The decision by regulators in the United States and European Union to ban BPA from baby bottles, combined with industry marketing campaigns, has convinced many consumers that the plastics and other containers currently used to store food are safe.

It is a false sense of security. BPA is still a constituent of many food containers, especially cans. And when companies did abandon BPA, they often adopted compounds - such as the increasingly common bisphenol S (BPS) - that share much of the same chemistry and raise many of the same concerns as BPA. "People use this chemical to replace BPA without sufficient toxicological information," says Kyungho Choi, an environmental toxicologist at Seoul National University. "That is a problem."

\section{FALL FROM GRACE}

BPA has formed the chemical backbone of most hard, clear polycarbonate plastic since the 1950s. Over time, studies have linked the chemical - which can leach out of plastics and into food - to a host of adverse health effects, including reductions in fertility and birth weight, male genital abnormalities, altered behavioural development, diabetes, heart disease and obesity ${ }^{1}$ (see Nature 464, 1122-1124; 2010).

Establishing a clear connection between a compound such as BPA and human health is complex, notes Geoffrey Greene, who studies oestrogens and their receptors at the University of Chicago in Illinois. "Most studies address only the question of whether such adverse effects can occur in various cell- or animal-based models," he says, "without addressing whether the amounts that we are exposed to are sufficient to have an effect on human health." Because many of the potential health effects of BPA are difficult to assess, the US National Institute of Environmental Health Sciences in Research Triangle Park, North Carolina, has launched a US\$30-million research programme designed to answer outstanding questions.

A few years ago, mounting evidence and concerned consumers convinced governments to take action. In 2011, the European Union banned BPA from baby bottles; the United States followed suit a year later. But BPA-based linings are still slathered on the insides of most food and beverage cans, and used to coat water-supply pipes in many countries. The compound is also found in dental sealants and in incubators for premature infants.

In the quest to replace BPA, finding an alternative for food and drink cans has proved particularly vexing. Creating a cheap lining for tins suitable for a range of foods - from beans to tomatoes to haggis curry - is no simple matter. Not only must the packaging prevent bacteria and fungi from attacking the food, the can's lining must also stop the food from attacking and corroding the can. Moreover, when metal comes into contact with food, it can ruin the flavour. "If your food tastes funny, but you tell people it's safer, are they going to believe that?" says Daniel Schmidt, a plastics engineer at the University of Massachusetts in Lowell.

Manufacturers also prefer linings that block sulphur compounds found in proteins, preservatives and pesticides - from reacting with the metal and forming unattractive iron or tin sulphide stains. No BPA-free lining has yet emerged that can accomplish all of this. "You have to have a special can and a special coating for every class of food," Schmidt says. "It gets extremely cumbersome and quite expensive."

BPA-based epoxy linings are widely used because they are strong, flexible and cheap. They tolerate the high temperatures needed to sterilize foods during canning, and do not interact with a huge array of foods and beverages, according to the North American Metal Packaging Alliance in Washington DC. The alliance estimates that 95\% of all aluminium and steel can coatings are epoxy-type resins: more than 99.9\% of these contain BPA.

And although there are alternatives, these are not without drawbacks. In 1999, Eden Organic of Clinton, Michigan, began coating bean tins with plant-based oleoresins. The switch has increased the cost of the tins by more than $20 \%$. Oleoresin linings can also alter the taste of food, and are vulnerable to attack from high-acid foods - such as tomatoes which have a particular propensity to leach BPA, according to biologist Frederick vom Saal of the University of Missouri-Columbia.

Some Japanese manufacturers now use reduced-BPA lacquers to coat cans. Other coatings include acrylics, which are too brittle for use in many tins, and vinyls and phenolics, both of which may have oestrogenic effects.

New options are beginning to surface. Schmidt is developing an epoxy based on a molecule in Tritan - a BPA-free polymer manufactured by the Eastman Chemical Company in Kingsport, Tennessee, that is used in baby bottles. He hopes that his epoxy will be as versatile and cheap as BPA. "The profit margins are so thin in the can-coating industry," he says. "Unless somebody hands them that solution, it's going to be tough for them to accept anything."

In contrast to the can-liner conundrum, replacing BPA in baby bottles and cash-register receipts proved relatively straightforward. When BPA fell from grace, many manufacturers turned to the compound's structural kin: BPS. A BPA molecule consists of two phenol groups connected by a branched three-carbon group. In a BPS molecule, the two phenol groups are instead connected by a sulphone group $\left(\mathrm{SO}_{2}\right)$.

BPS was first made in 1869 as a dye. But because it was introduced into consumer goods only recently — into cash-register receipts in 2006, for example - few researchers have studied its toxicity. "The main question, to which we have no answer, is: 'is BPS as toxic as BPA?"” says René Habert, an endocrinologist at Paris Diderot University.

\section{A KEY TO ACTION}

The similarity of BPS's structure to that of BPA is enough to raise suspicions that it may mimic oestrogens, says Cheryl Watson, a biochemist at the University of Texas Medical Branch in Galveston. Natural oestrogens are small molecules containing several phenolic rings; these bear chemical adornments that bind to a pocket found in oestrogen receptors in the body. BPA and BPS are about the same size and have similar phenolic rings with similar attachments, so they may slot like keys into oestrogen receptors, Watson says.

Watson and a colleague, Rene Viñas, now at the US Food and Drug Administration, measured the responses of cultured rat pituitary cells to BPS. These cells are particularly sensitive to oestrogens and oestrogen mimics, allowing the team to study concentrations of BPS down to $10^{-15}$ moles per litre. The team found that even at these very low levels, BPS triggered the enzyme cascade normally activated by an oestrogen called oestradiol ${ }^{2}$, an effect also seen with BPA. When combined with levels of oestradiol found in adult women, BPS seemed to over-stimulate the pathway, shutting it down and causing cell suicide. The results, says Watson, were typical of those expected of an oestrogen mimic: inappropriate activation of oestrogen responses, disruption of normal oestrogen-response pathways, and eventual cell death.

Others have seen similar effects. Susanne Bremer and her colleagues at the Institute for Health and Consumer Protection, a European Commission-funded research centre in Ispra, Italy, tested BPS and BPA on an oestrogen-sensitive human cell line. They found that both chemicals behaved like oestrogens, but were 100,000-fold less active than oestradiol $^{3}$. Choi and his colleagues discovered that zebrafish exposed to 0.5 micrograms of BPS per litre of water - about one-sixth of the maximum concentration detected in the environment - had fewer eggs, more malformed offspring and higher oestrogen to testosterone ratios than untreated zebrafish". "High concentrations of BPS have the same effect as high concentrations of BPA," says Habert, who has conducted 
preliminary experiments on the effect of BPS on mouse and human fetal testis cells. "At low concentrations, the effect is unknown."

What concentration best approximates human exposure to BPS is not clear. A team led by Catherine Simoneau of the Institute for Health and Consumer Protection analysed a total of 30 BPS-containing baby bottles from 12 countries. After five minutes in boiling water and two hours at $70^{\circ} \mathrm{C}$, none of the bottles released detectable quantities of BPS ${ }^{5}$. "These materials are far more resistant to hydrolytic breakdown than polycarbonate - that was one of the big selling points," says Schmidt. "As such, I would consider them to be safer than polycarbonate in a food-contact setting."

But people are exposed to BPS in many different ways. Kurunthachalam Kannan, an analytical chemist at the New York State Department of Health in Albany, and his team have found BPS on cash-register receipts, and aeroplane luggage tags and boarding passes, all of which are made from thermal paper containing BPS as a colour developer. The scientists also found BPS in products made from recycled paper, including pizza boxes and food buckets.

Kannan's team estimates that the average daily exposure to BPS through the skin is well below the threshold values for toxic effects. Nevertheless, given the potential for higher levels of exposure from other sources such as food, Kannan urges further studies of the compound. And Watson argues that even small amounts of oestrogen mimics can cause trouble. "The problem is that they are active in such small quantities," she says. "If you leach even a little, you still leach enough for responses to happen."

\section{BRANCHING OUT}

Some manufacturers have left the bisphenol family in search of a replacement. In 2007, the Eastman Chemical Company launched Tritan - a new heat-resistant clear plastic - for infant-care products such as baby bottles. This BPA-free plastic has since replaced the old BPAcontaining polycarbonate in many water bottles, food containers and children's cups. Eastman says that the results of testing, analysed by Thomas Osimitz of Science Strategies, a consulting firm in Charlottesville, Virginia, and his colleagues, verified that Tritan's monomers do not bind to oestrogen or androgen receptors ${ }^{6}$.

In 2011, George Bittner, a neurobiologist at the University of Texas at Austin and the chief executive of Austin-based chemical-testing company CertiChem, reported that $92 \%$ of 102 commercially available plastic products leached chemicals with oestrogenic activity ${ }^{7}$. This included plastics advertised as BPA-free. The reason, Bittner says, is that additives in plastics — such as stabilizers and lubricants — can also bind to oestrogen receptors, as can some of the plastic monomers themselves.

Tritan resins produced by Eastman were among the polymers that showed oestrogenic activity in Bittner's assays. When PlastiPure, a sister company of CertiChem, produced a brochure publicizing these results, Eastman sued. The company's lawyers maintained that the in vitro test used by CertiChem - which involved oestrogen-sensitive breast cancer cells grown in culture - is not a definitive assay for oestrogenic activity. In a letter to the editor of the journal Food and Chemical Toxicology, Bittner countered that his assays are up to 200 times more sensitive than the tests Osimitz analysed to demonstrate Tritan's safety ${ }^{8}$.

Bittner had support: Wade Welshons, who studies endocrine disruptors at the University of Missouri-Columbia, independently tested five Tritan bottles using the same assay as Bittner. In a deposition entered during the trial, Welshons reported that he found detectable oestrogenic activity in each test. But the jury ruled in Eastman's favour, and the judge barred Bittner, PlastiPure and CertiChem from making claims about Tritan's oestrogenic activity.

Eastman stands by the results reported by Osimitz. And, unlike Bittner, Welshons suspects that the oestrogenic activity he found is attributable not to the Tritan polymer itself, but to other compounds added during plastics manufacturing. $\mathrm{He}$ is not the only one concerned about the complex mixtures of chemicals used to make plastics. In 2012, the world produced some 280 million tonnes of plastic. According to a model based on the United Nations' Globally Harmonized System of Classification and Labelling of Chemicals, more than $50 \%$ of these plastics contain ingredients that can be hazardous (see Nature 494, 169-171; 2013). Some are carcinogenic; others are oestrogenic.

It is not yet clear how many of these chemicals are dangerous at the concentrations found in the plastics. But mixed together, the chemicals could have synergistic effects. Watson and Viñas recently studied the effect of the oestrogen mimics BPA, BPS and nonylphenol (a detergent precursor) on cultured rat pituitary cells. They found that a combination of two or three of the compounds caused greater disruption to the oestrogen-signalling system - and did so at lower concentrations - than did a single compound". "We don't experience any of these chemicals alone," Watson says. "A lot of other chemicals mimic oestrogens."

Ideally, says Watson, the next generation of chemicals would be tested for effects on oestrogen signalling before widespread deployment in food containers. To that end, she and a group of biologists and chemists have put together a plan called TiPED, or Tiered Protocol for Endocrine Disruption. Under this testing system, newly synthesized chemicals would be evaluated for endocrine-disrupting potential at five different stages, from initial computational analysis of structure to whole-animal experiments.

The goal is to form a consortium of independent laboratories that would test chemicals on request by plastics companies. Convincing these companies to participate will be a challenge, Watson acknowledges. But there is an incentive, she argues, because companies can suffer from bad press, lost business and lawsuits when a chemical they produce or use is linked to human health concerns. "When it gets proved that an individual chemical is a problem," says Watson, "they're going to have to, as an industry, completely retool."

The TiPED proposal is designed to ensure that endocrine-disrupting chemicals no longer reach the market. For Watson and many other researchers, the current situation raises concern because there are so many untested compounds found in countless plastic products. Those chemicals, she says, "are really all around us".

\section{Josie Glausiusz is a freelance journalist in Ra'anana, Israel.}

1. Rochester, J. R. Reprod. Toxicol. 42, 132-155 (2013).

2. Viñas, R. \& Watson, C. S. Environ. Health Perspect. 121, 352-358 (2013).

3. Grignard, E. Lapenna, S. \& Bremer, S. Toxicol. in Vitro 26, 727-731 (2012).

4. Ji, K., Hong, S., Kho, Y. \& Choi, K. Environ. Sci. Technol. 47, 8793-8800 (2013).

5. Simoneau, C., Valzacchi, S., Morkunas, V. \& Van den Eede, L. Food Addit. Contam. 28, 1763-1768 (2011).

6. Osimitz, T. G. et al. Food Chem. Toxicol. 50, 2196-2205 (2012).

7. Yang, C. Z., Yaniger. S. I., Jordan, V. C., Klein, D. J. \& Bittner, G. D. Environ. Health Perspect. 119, 989-996 (2011).

8. Bittner, G. \& Yaniger, S. Food Chem. Toxicol. 50, 4236-4237 (2012).

9. Viñas, R. \& Watson, C. S. Environ. Health 12, 26 (2013). 